\title{
Molecular diagnosis of tomato leaf curl virus disease
}

\author{
Md Mostafa Kamal, Sujay Kumar Bhajan, Nadra Tabassum, and Mohammad Nurul Islam*
}

\begin{abstract}
Tomato leaf curl virus disease (ToLCVD) is one of the major causes for maximum yield loss of tomato. This disease is caused by tomato leaf curl viruses (ToLCV) belongs to the genus Begomovirus. The infected plants emerge with severe leaf curling, puckering, and yellow margin, reduced leaf size and stunted growth. Tomato leaf curl symptoms caused due to physiological reason sometimes may misguide the farmer for proper identification. In this study, we described about the molecular diagnosis of ToLCVD in the samples collected from six major tomato cultivating areas of Bangladesh. Molecular methods were followed to diagnose and characterize tomato leaf curl virus coat protein (CP) gene. We have isolated total DNA from symptomatic leaves and subjected to rolling circle amplification (RCA). Restriction digestion, polymerase chain reaction $(\mathrm{PCR})$ and sequencing was performed using the RCA products. The coat protein of ToLCV was sequenced by the begomovirus specific "BGCP" forward and reverse primers. The partial sequences of all the six isolates showed more than $90 \%$ nucleotide (nt) identities with tomato leaf curl virus coat protein (CP) gene. The technique describe above can be applied for the easy and proper molecular diagnosis of the ToLCVD for the development of sustainable strategies to manage this disease.
\end{abstract}

Keywords-Begomovirus; CP; Diagnosis: Phylogeny; RCA; ToLCV

\section{Introduction}

Tomato (Solanum lycopersicum L.) is the world's fourth most important vegetable crop with an annual production of 162 million metric tons [1]. It belongs to the family Solanaceae and cultivated throughout the world. The main reason of low yield or production loss is due to its susceptibility to various pests and diseases. More than 200 pathogens have reported those infect this crop [2]. Besides fungal, bacterial and physiological diseases, it is also affected by several viral diseases. Tomato leaf curl viruses (ToLCVs) are one of the major causal agents those are responsible for the maximum yield loss. The devastating effect of ToLCV is common all over the world and now-adays the tropics and sub-tropics have become a prone zone of ToLCV [3, 4]. Tomato leaf curl viruses are the plant viruses of Geminiviridae family and known as geminiviruses. They are characterized by double icosahedral particles and their circular single stranded DNA (ssDNA) [5]. ToLCV under the genera Begomovirus may present in bipartite type (both DNA-A and DNA-B of $2.7 \mathrm{~kb}$ bp with a mutual $\sim 200$ bp region) or monopartite type (very much similar to DNA-A) [6, 7]. The vector of ToLCV is mainly Whiteflies (Sweet potato whitefly Bamesia tabaci and Silver leaf whitefly $B$. argentifolii) which attack mainly dicotyledonous crop plants $[8,9]$.

Md Mostafa Kamal, Sujay Kumar Bhajan, Nadra Tabassum, and Mohammad Nurul Islam

Department of Botany, University of Dhaka, Dhaka-1000 Bangladesh
Most of the ToLCV from Taiwan, Australia \& Indian subcontinent are monopartite and only contain DNA-A [10, 11]. The function of DNA-A component is to encode signals for six most important viral factors such as- the coat protein (CP) - AV1; the pre-coat protein-AV2; the viral replicationassociated protein (Rep) -AC1 [12]; the transcription activator protein (TrAP) -AC2 [13, 14, 15]; the replication enhancer protein- AC3 [16]; and protein for putative symptom expression-AC4 [15, 17]. DNA-B encodes two important movement proteins, $\mathrm{BV} 1$ and $\mathrm{BC} 1$, responsible for nuclear shuttling and cell-to-cell long distance movement $[18,19]$. Spotting of ToLCVD in Bangladesh and its devastating effect in production emerged the importance of studying this disease. In this regard study of this disease from the molecular point of view and its causal pathogen, distribution, molecular variability, potential economic loss and a sustainable solution have become an important issue. In 1996 the first natural recombination with enhanced pathogenicity between two begomovirus species was reported [20]. Later in 2008 Chakrabarty et al. [21] reported an asymmetric synergism and virulent pseudorecombinant, and again enhanced pathogenicity was found when tested in some Solanaceae plants. The most notorious problem of geminiviruses is the emergence of new strains within a same geographical location. As a result novel gemimniviruses can exploit new ecological niches [22]. Natural recombination among three strains of tomato leaf curl Bangalore viruses and the possibility of recombination between species that can co-exist within a same geographical location was reported [23]. This paper describes the molecular aspects for diagnosis of this disease of infected plants collected from six different tomato growing regions. From the evolutionary point of view molecular diagnosis and characterization of this disease has become imperative.

Identifying the coat protein $(\mathrm{CP})$ gene from the isolated DNA of infected leaves can assure the presence of ToLCV and thus diagnosing the reason of leaf curl disease. The $\mathrm{CP}$ gene is encoded by A component. This CP is responsible for the attachment of the virus and accumulation of ssDNA into the $[22,24]$. The $\mathrm{CP}$ leaves the cell after a successful infection phase in the cell. Several recent studies have emerged that the $\mathrm{CP}$ of plant virus has the potential to be used in various practical purposes along with development of virus resistant varieties [25]. Another Begomovirus Tomato Yellow leaf curl virus (TYLCV) resistant plant has been reported by silencing its $\mathrm{CP}$ expression via producing siRNA [26]. So far no report has published on antiviral strategies to develop ToLCV resistant variety in Bangladesh. In this study, we described the molecular diagnosis tomato leaf curl virus disease and characterization of its $\mathrm{CP}$ from different samples of Bangladesh.

\section{Abbreviations and Acronyms}

ToLCVD- tomato leaf curl virus disease; ToLCVtomato leaf curl virus; $\mathrm{CP}$ - coat protein; RCA- rolling circle amplification; BGCP- Begomovirus coat protein; nt- 
nucleotide; ssDNA- single stranded DNA; PCR- polymerase chain reaction; siRNA- short interference RNA; ToLCVBDdk- tomato leaf curl virus-Bangladesh Dhaka strain; ToLCV-BDcd- tomato leaf curl virus-Bangladesh Comilla debidwar strain; ToLCV-BDce- tomato leaf curl virusBangladesh Comilla elahabad strain; ToLCV-BDjp- tomato leaf curl virus-Bangladesh Jamalpur strain; ToLCV-BDmgtomato leaf curl virus-Bangladesh Munshiganj strain; ToLCV-BDk- tomato leaf curl virus-Bangladesh Kushtia strain; TYLCV- tomato yellow leaf curl virus; CTABcetyltrimethylammonium bromide

\section{Materials and Methods}

\section{Plant materials:}

Infected curled tomato leaves were collected from six different tomato growing regions of Bangladesh (Dhaka, Debidwar, Elahabad, Jamalpur, Munshiganj \& Kushtia).

\section{DNA \\ Sampling, Identification and extraction of}

The primary detection was done by observing the whitefly association with plants. The infected plants were dwarfed due to stunted growth, reduced leaf size with curling and puckering of leaflets. Modified Cetyltrimethylammonium bromide (CTAB) method of Islam and Mukherjee [27] was used to isolate the total DNA from infected leaves.

\section{Rolling Circle Amplification, restriction digestion and Polymerase chain reaction}

The total DNA was subjected to rolling circle amplification (RCA), using the TempliPhi 100 amplification kit (Amersham Biosciences, USA). The RCA products were digested with BamHI and SacI restriction enzymes separately to see the presence of a $2.7 \mathrm{~kb}$ band as expected for ToLCV genome size. The begomovirus specific BGCPF (5'-TGTGARGGYCCWTGYAARGTYCA-3') and BGCPR (5'-TASARGCATGWGTACANGCCATATAC-3') primers (Pandey et al., 2010) were used to amplify the coat protein gene from the RCA products in a standard PCR reaction. An aliquot of PCR \& restriction digestion reaction products was checked in $1.0 \%$ agarose gel to inspect the amplification.

\section{Sequence analysis and phylogetic study}

The PCR amplified CP gene products were purified by GeneJet PCR purification kit (Thermo scientific). The purified CP gene was sequenced. The obtained sequenced data from all samples were analyzed using NCBI-BLAST database search program. This allowed comparing the sequenced $\mathrm{CP}$ gene with any reported coat protein around the world to be confirmed that the amplified DNA is the coat protein gene of ToLCV. Phylogenetic tree was constructed from the obtained sequences and other reported data from worldwide. The software MEGA 6.0 program was used to construct the Phylogenetic tree, where neighbor joining and maximum likelihood methods with 100 bootstrap replications were used.

\section{Results}

\section{Primary confirmation of disease indication}

Tomato plants with severe leaf curling were observed in the fields from different regions of Bangladesh. Symptomatic leaves with severe infections were collected and studied in the laboratory. (Fig.1)

Total DNA was isolated from the infected leaves to diagnose the presence of the suspected causal agent from begomovirus genera. In the first step, $\Phi 29$ polymerase based rolling circle amplification (RCA) was performed with the isolated DNA to amplify the ToLCV genome. Restriction digestion of the RCA product with BamHI, SacI, and HindIII showed amplification of $\sim 2.7 \mathrm{~kb}$ (Fig-2, a) in case of infected samples. The presence of begomovirus in the infected DNA can be implied by this $\sim 2.7 \mathrm{~Kb}$ amplification. For further confirmation about the causal agent as "begomovirus" RCA products were subjected to polymerase chain reaction (PCR) using begomovirus coat protein specific forward and reverse primers. In gel electrophoresis the PCR products showed an amplification of $\sim 500 \mathrm{bp}$ (Fig2 , b) fragment. This amplification again indicated the presence of begomovirus as expected, which was finally confirmed through DNA sequence analysis. All the sequenced samples were designated as ToLCV-BDdk (Dhaka), ToLCV-BDcd (Comilla Debidwar), ToLCV-BDce (Comilla Elahabad), ToLCV-BDjp (Jamalpur), ToLCVBDmg (Munshiganj) \& ToLCV-BDk (Kushtia).

\section{Confirmation of Begomovirus}

Partial sequences of all six samples were analyzed through NCBI-BLAST program database search system. Obtained results from the BLAST database showed that all the samples have more than $90 \%$ nucleotide (nt) identities with tomato leaf curl virus (ToLCV) coat protein (CP) gene reported from this geographic area as well as with others from worldwide (Table-1). Besides, most of them have similarities with reported tomato leaf curl virus from Bangladesh, such as ToLCV-BDdk (Dhaka), ToLCV-BDcd (Comilla Debidwar) and ToLCVs-BDk (Kushtia) has 93\%, $92 \%$, and $91 \%$ nucleotide identity with Tomato leaf curl Bangladesh virus complete genome (GeneBank:AF188481.1) respectively. Again ToLCVsBDdk and ToLCVs-BDk showed $95 \%$ and $94 \%$ identical to Tomato leaf curl virus coat protein (AV1) gene, complete cds (GeneBank:AY690431.1) separately. Whereas, ToLCVs-BDdk and ToLCVs-BDed has shared 92\% and $91 \%$ nucleotide similarities with Tomato leaf curl Bangladesh virus isolate GUW-1 coat protein (AV1) gene, complete cds (GeneBank:JF825866.1). Along with this three, ToLCV-BDce has $93 \%$ nt identity with Tomato leaf curl New Delhi virus-Severe (Jessore) segment DNA-A, complete sequence (GeneBank:AJ875157.1) and Tomato leaf curl New Delhi virus coat protein (AV1) gene, complete cds (GeneBank:GQ225737.1) severally. The other two samples from Jamalpur (ToLCV-BDjp) and Munshiganj (ToLCV-BDmg) shared $95 \%$ and $94 \%$ nt sequence similarities respectively, with Tomato leaf curl Patna virus segment DNA-A, complete sequence (GeneBank:EU862323.1). In all the cases E-value was zero or less than zero, which indicates a good hit over the database. ToLCV-BDjp is also $90 \%$ identical to Tomato leaf curl Patna virus isolate JM-AS-1 coat protein (AV1) gene, complete cds (GeneBank:JN381198.1). 


\section{Phylogenetic analysis}

The analysis of Phylogenetic study on the basis of nucleotide sequences of the coat protein (CP) genes of all the six samples with $\mathrm{CP}$ sequences of other selected tomato leaf curl viruses showed a close relationship among them. In case of both Maximum likelihood and Neighbor joining methods (Fig-3). This study revealed that, the ToLCV-BDdk and ToLCV-BDk clusters with tomato leaf curl virus (ToLCV CP) but they form a separate clade. The closest ancestors of these two sample isolates are different strains of Tomato leaf curl Bangladesh virus (ToLCV-BD). But way behind the evolutionary line the ToLCV-BDcd (Comilla Debiwar) is the ancestral parent to all of these begomoviruses. Similarly the ToLCV-BDce has evolved as the ancestor of Tomato leaf curl New Delhi virus, which has shared $100 \%$ bootstrap values. The other two samples from Jamalpur (ToLCV-BDjp) and Munshiganj (ToLCV-BDmg) has homology with Tomato leaf curl Patna virus, which seems to be the major parent.

\section{Discussion}

The rolling circle amplification (RCA) technique has become a common and reliable tool for studying molecular characters of viruses which have circular genomes [28]. This is an isothermal, enzymatic process, which synthesize numerous copies of long single stranded (ss) DNA using short circular ssDNA templates [29]. The RCA of the total DNA from all six samples copied and separated only the ssDNA of the tomato leaf curl virus (ToLCV). Thus, restriction digestion produced $2.7 \mathrm{~kb}$ amplification on gel electrophoresis. The Coat Protein is the most conserved region of ToLCV genome [30, 31]; therefore the BGCP forward (BGCPF) \& reverse (BGCPR) degenerate primer pairs were used to amplify the conserved region of ToLCV $\mathrm{CP}$ genes as the primer pair is designed to amplify any begomovirus coat protein gene [32]. Degenerate primers have been used in several other studies to amplify the coat protein region of ToLCVs $[33,34]$.

Since the CP genes are highly conserved region in begomoviruses, it can be used to identify the presence of this genus. According to International Committee on Taxonomy of Viruses (ICTV) begomoviruses can be predicted through $\mathrm{CP}$ gene sequences when complete genomic sequences are not available $[35,36]$. The NCBIBLAST database search and multiple sequence alignment showed more than $90 \%$ sequence similarities with several previously reported ToLCV coat protein (CP) gene. More than $90 \%$ nucleotide sequence identity has been suggested as a guideline for predicting viral strain and less than $90 \%$ for distinct begomovirus strain [36].

The Phylogenetic study and NCBI-BLAST search results for the $\mathrm{CP}$ sequences clearly indicates that the isolated six virus strains from the infected tomato leaves are ToLCV strains. The constructed phylogenetic tree suggests the closeness and evolutionary relationship among the ToLCVs.

\section{Conclusion}

All the obtained data indicate that the molecular methods and approaches we followed can be used as a molecular tool for rapid diagnosis of tomato leaf curl virus disease in different plant pathology clinics.

\section{Figures and Tables}
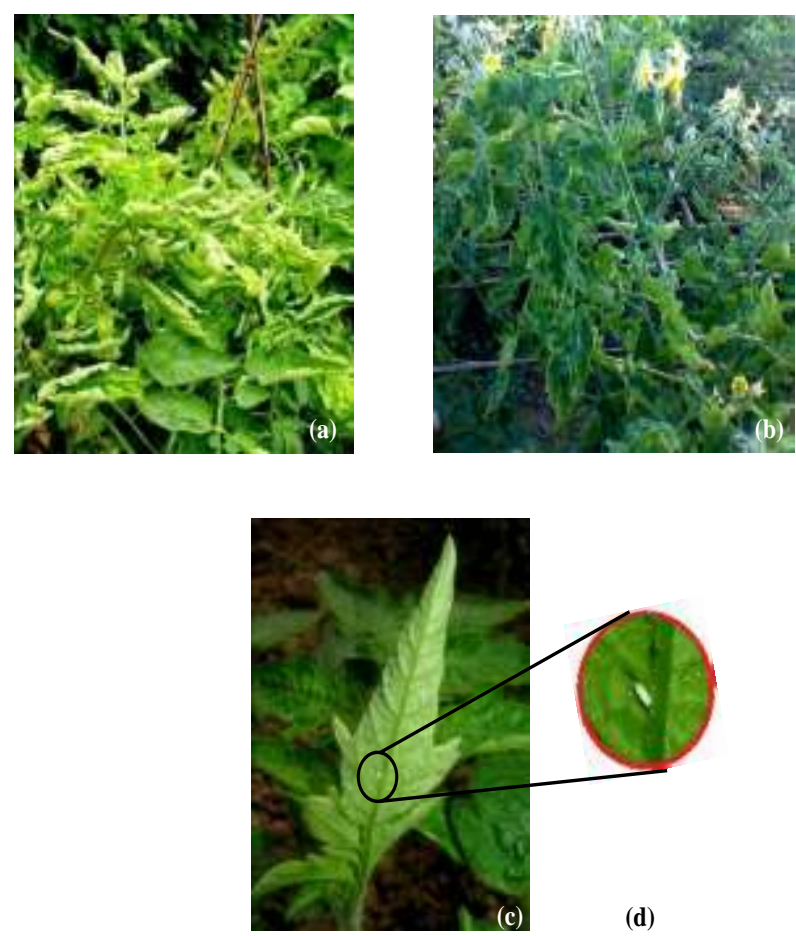

Figure 1. Tomato Leaf Curl Virus (ToLCV) infected leaf samples of tomato collected from Comilla and Jamalpur. Symptoms at different stages of tomato plant \& Whitefly association a) Leaf curl symptom appeared in young stage, b)Symptoms during flowering and fruiting stage, c) Leaf curl symptom with whitefly and d) Magnified view of Whitefly.

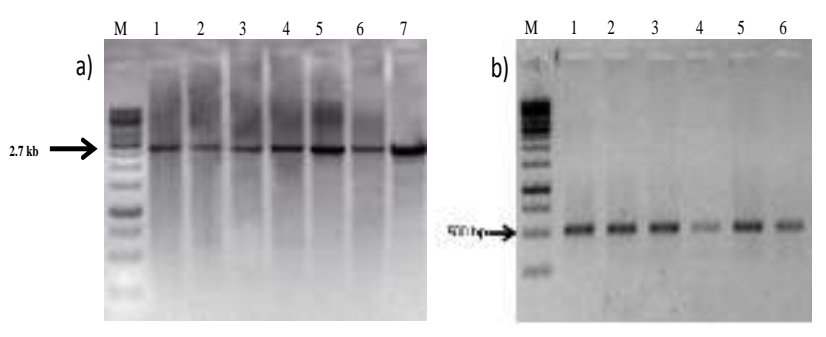

Figure 2. Restriction digestion of RCA products and PCR amplification of coat protein (CP) gene. a) RCA products of six samples were digested with $\mathrm{BamHI}$ and separated on $1 \%$ agarose gel. Lane $\mathrm{M}$ is the marker \& lane 1 to 6 representing the samples ToLCV-BDdk, ToLCV-BDjp, ToLCVBDmg and ToLCV-BDk correspondingly and lane 7 is the PCR control, all of them showing $\sim 2.7 \mathrm{~Kb}$ amplification and $\mathrm{b}$ ) Polymerease chain reaction was performed by BGCPF \& BGCPR primer pairs for the samples as mentioned in figure $2 \mathrm{a}$ and showing $\sim 500 \mathrm{bp}$ amplification after separating on $1 \%$ agarose gel. 
Proc. of the Third Intl. Conf. Advances in Bio-Informatics, Bio-Technology and Environmental Engineering- ABBE 2015 Copyright (c) Institute of Research Engineers and Doctors, USA .All rights reserved.

ISBN: 978-1-63248-060-6 doi: 10.15224/ 978-1-63248-060-6-02

Table 1. Per cent identities (nucleotide) of newly isolated ToLCV CP genes from six different samples from Bangladesh with reported $\mathrm{CP}$ genes from various geographic area.

\begin{tabular}{|c|c|c|c|c|c|c|}
\hline Sample & $\begin{array}{c}\text { Highest } \\
\text { identity with }\end{array}$ & $\begin{array}{l}\text { Max } \\
\text { score }\end{array}$ & $\begin{array}{l}\text { Total } \\
\text { score }\end{array}$ & $\begin{array}{c}\text { Query } \\
\text { cover } \\
\text { age } \\
(\%)\end{array}$ & $\begin{array}{c}\mathrm{E} \text { - } \\
\text { value }\end{array}$ & $\begin{array}{c}\text { Identi } \\
\text { ty }\end{array}$ \\
\hline \begin{tabular}{|c} 
Tomato leaf curl \\
virus - \\
Bangladesh \\
Dhaka (ToLCV- \\
BDdk)
\end{tabular} & 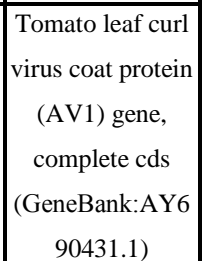 & 725 & 725 & $93 \%$ & 0.0 & $95 \%$ \\
\hline \begin{tabular}{|c} 
Tomato leaf curl \\
virus - \\
Bangladesh \\
Comilla \\
Debidwar \\
(ToLCV-BDcd)
\end{tabular} & \begin{tabular}{|c|} 
Tomato leaf curl \\
Bangladesh virus \\
complete \\
genome \\
$(\mathrm{AF} 188481.1)$
\end{tabular} & 623 & 623 & $93 \%$ & $5 \mathrm{e}-175$ & $92 \%$ \\
\hline \begin{tabular}{|c} 
Tomato leaf curl \\
virus - \\
Bangladesh \\
Comilla Comilla \\
Elahabad \\
(ToLCV-BDce
\end{tabular} & \begin{tabular}{|c|} 
Tomato leaf curl \\
New Delhi virus- \\
Severe(Jessore) \\
segment DNA- \\
A, complete \\
sequence \\
(GeneBank:AJ87 \\
$5157.1)$
\end{tabular} & 658 & 658 & $90 \%$ & 0.0 & $93 \%$ \\
\hline $\begin{array}{c}\text { Tomato leaf curl } \\
\text { virus - } \\
\text { Bangladesh } \\
\text { Jamalpur } \\
\text { (ToLCV-BDjp) }\end{array}$ & $\begin{array}{c}\text { Tomato leaf curl } \\
\text { New Delhi virus } \\
\text { coat protein } \\
\text { (AV1) gene, } \\
\text { complete cds } \\
\text { (GeneBank:GQ2 } \\
\text { 25737.1) }\end{array}$ & 658 & 658 & $90 \%$ & 0.0 & $93 \%$ \\
\hline $\begin{array}{c}\text { Tomato leaf curl } \\
\text { virus - } \\
\text { Bangladesh } \\
\text { Munshiganj } \\
\text { (ToLCV-BDmg) }\end{array}$ & $\begin{array}{c}\text { Tomato leaf curl } \\
\text { Patna virus } \\
\text { isolate JM-AS-1 } \\
\text { coat protein } \\
\text { (AV1) gene, } \\
\text { complete cds } \\
\text { (GeneBank:JN38 } \\
1198.1)\end{array}$ & 736 & 736 & $93 \%$ & 0.0 & $95 \%$ \\
\hline \begin{tabular}{|c|} 
Tomato leaf curl \\
virus - \\
Bangladesh \\
Kushtia \\
(ToLCV-BDk)
\end{tabular} & 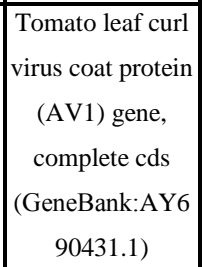 & 671 & 671 & $89 \%$ & 0.0 & $94 \%$ \\
\hline
\end{tabular}

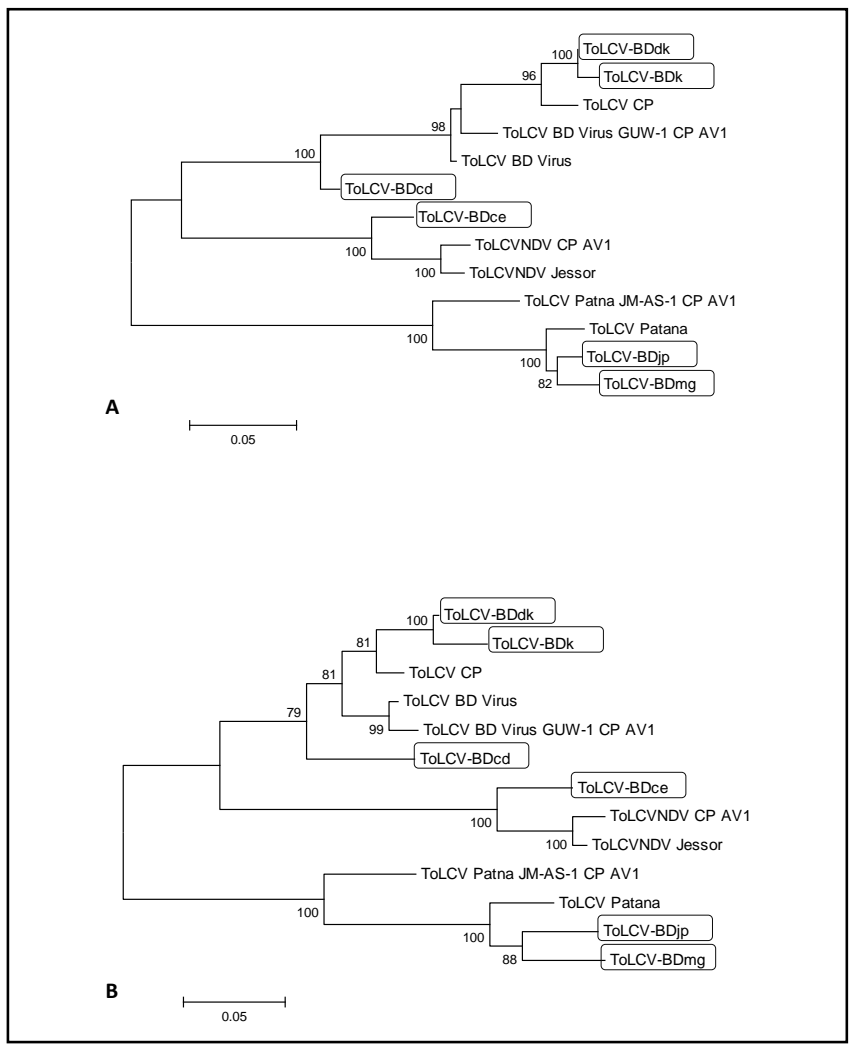

Figure 3 - Phylogenetic tree of coat protein (CP) gene sequences of the samples and selected tomato leaf curl viruses. The phylogenetic trees were constructed by maximum likelihood (a) and neighbor-joining method (b) with 100 bootstrap replications using MEGA -6. Samples are mentioned in this study are boxed.

\section{Acknowledgment}

The work was supported by the grants received from the International Centre for Genetic Engineering and Biotechnology (ICGEB), Trieste, Italy. All the experiments were conducted in Plant Breeding and Biotechnology Laboratory, Department of Botany university of Dhaka. Authors are thankful to Centre for Advanced Research in Sciences (CARS), University of Dhaka for providing sequencing facilities.

\section{References}

[1] FAO STAT Top-20 Countries by Commodities, 2012.

[2] J.B. Jones, R.E. Stall, and T.A. Zitter, "Compendium of Tomato Diseases," The APS press Minnesota, USA, 1997, p 4-13.

[3] S. Chakraborty, P. K. Pandey, M. K. Banerjee, G. Kallo, and C. M. Fauquet, "Tomato leaf curl Gujarat virus, a new begomovirus species causing a severe leaf curl disease of tomato in Varanasi, India," Virol. vol. 93, no. 12, pp. 1485-1495, December 2003.

[4] R. Fazeli, J. Heydarnejad, H. Massumi, and M. Shaabanian, A. Varsani, " Geneticdiversity and distribution of tomato-infecting begomoviruses in Iran," Virus. Genes. vol. 38, pp. 311-319, April 2009.

[5] J. E. Thomas, P. R. Massalski, and B. D. Harisson, "Production of monoclonal antibodies to african cassava mosaic virus and differences in their reactivities with other whitefly transmitted reminiviruses," J. Gen. Virol. Vol. 67, pp. 2739-2748, September 1986.

[6] A. Kheyr-Pour, M. Bendahmane, V. Matzeit, G.P. Accotto, S. Crespi, and B.Gronenborn, "Tomato yellow leaf curl virus from Sardinia is a 
whitefly transmitted monopartite geminivirus," Nucleic. Acids. Res. Vol. 19, pp. 6763-6769, December 1991.

[7] N. Navot, E. Pichersky, M. Zeidan, D. Zamir, and H. Czosnek, Tomato yellow leaf curl virus: a whitefly-transmitted geminivirus with a single genomic component. Virology. vol. 185 , no. 01, pp. 151161, November 1991.

[8] J. W. Davies and J. Stanley, "Geminivirus genes and vectors," Trends Genet. vol. 5, pp. 77-81, 1989.

[9] M.J. Melzer, D.Y. Ogata, and S.K. Fukuda, "First report of tomato yellow leaf curl virus in Hawaii," Plant Disease. vol. 94, pp. 641.2 641.2, May 2010

[10] R.W. Briddon, J. K. Brown, and E. Moriones, "Recommendations for the classification and nomenclature of the DNA- $\beta$ satellites of begomoviruses," Arch. Virol. vol. 153, no. 4, pp. 763-781, April 2008.

[11] I.B. Dry, L.R. Krake, J.E. Rigden, M.A. Rezaian "A novel sub viral agent associated with a geminivirus: The first report of a DNA satellite,” Proc. Natl. Acad. Sci. USA. vol. 94, pp. 7088-7093, June 1997.

[12] J. Laufs, I. Jupin, C. David, S. Schumacher, F. Heyraud-Nitschke, and B. Gronenborn, "Geminivirus replication: genetic and biochemical characterization of rep protein function, a review," Biochimie. vol.77, pp. 765-773, September 1995.

[13] G. Sunter, D. M. Bisaro, "Transactivation in a geminivirus AL2 gene product is needed for coat protein expression," Virol. vol. 180, pp. 416-419, January 1991

[14] G. Sunter, and D. M. Bisaro, "Transactivation of geminivirus AR1 and BR1 gene expression by the viral AL2 gene product occurs at the level of transcription," Plant. Cell. vol. 4, pp. 1321-1331, October 1992.

[15] R. Vanitharani, P. Chellappan, S. Justin, and M. Claude, "Differential Roles of $\mathrm{AC} 2$ and $\mathrm{AC} 4$ of cassava geminiviruses in mediating synergism and suppression of posttranscriptional gene silencing," J. Virol. vol. 78(17), pp. 9487-9498, September 2004.

[16] G. Sunter, M. D. Harititz, S. G. Hormuzdi, C. L. Brough, and D. M. Bisaro, "Genetic analysis of tomato golden mosaic virus: ORFAL2 is required for coat protein accumulation while ORF AL3 is necessary for efficient DNA replication,” Virol. Vol. 179, pp. 69-77, November 1990.

[17] R. Van Wezel, X. Dong, P. Blake, J. Stanley, and Y. Hong, "Differential roles of geminivirus Rep and AC4 (C4) in the induction of necrosis in Nicotiana benthamiana," Mol. Plant. Pathol. Vol. 3, pp. 461-471, November 2002.

[18] A. Sanderfoot, and S. G. Lazarowitz, "Getting it together in plant virus movement: cooperative interactions between bipartite geminivirus movement proteins," Trends. Cell. Biol. Vol. 6, pp. $353-$ 358, September 1996

[19] M. Hussain, S. Mansoor, S. Iram, A.N. Fatima, and Y. Zafar, "The nuclear shuttle protein of tomato leaf curl New Delhi virus is a pathogenicity determinant," J. Virol. vol. 79, pp. 4434-4439, April 2005.

[20] Y.M. Hou, and R.L. Gilbertson "Increased pathogenicity in a pseudorecombinant bipartite geminivirus correlated with intermolecular recombination," J. Virol. vol.70, no. 8, pp. 5430-5436, August 1996.

[21] S. Chakraborty, R.Vanitharani, B. Chattopadhyay, C. M. Fauquet "Supervirulent pseudorecombination and asymmetric synergism between genomic components of two distinct species of begomovirus associated with severe tomato leaf curl disease in India," J. Gen. Virol. vol.89, no.3, pp. 818-828, March 2008.

[22] M. Padidam, S. Sawyer, and C.M. Fauquet, "Possible emergence of new geminiviruses by frequent recombination," Virology. vol. 265, pp. 218-225, December 1999.

[23] N. Kirthi, S.P. Maiya, M.R.N. Murthy, H.S. Savithri, "Evidence for recombination among the tomato leaf curl virus strains/ species from Bangalore, India,” Arch. Virol. vol. 147, pp. 255-272, February 2002.

[24] S. Qin, B. M .Ward, and S. G. Lazarowitz, "The bipartite geminivirus coat protein aids BR1 function in viral movement by affecting the accumulation of viral single-stranded DNA," J. Virol. Vol.72, pp. 9247-9256, November 1998.

[25] M. Prins, M. Laimer, E. Noris, J. Schubert, M. Wassenegger, and M. Tepfer, "Strategies for antiviral resistance in transgenic plants," Mol . Plant . Pathol, vol. 9, pp. 73-83, January 2009.

[26] A. Zrachya, P.P. Kumar, and U. Ramakrishnan, "Productionof siRNA targeted against TYLCV coat protein transcripts leads to silencing of its expression and resistance to the virus," Transgenic Res. vol. 16, no. 02, pp. 385-389, June 2007.

[27] M.N. Islam, and S.K. Mukherjee "Construction of MYMIV based gene silencing vector and its use. ISBN: 978-3-8443-8820-6. LAP-LAMBERT Academic Publishing Gmb H \& Co. KG. Dudweiler Landstr. 99, 66123 Saarbrücken, Germany. 2011.

[28] A. Fire, S.Q. Xu, "Rolling replication of short DNA circles," Proc. Natl. Acad. Sci. USA. vol. 92, pp. 4641-4645, May 1995.

[29] W. Zhao, M. M. Ali, M. A. Brook, and Y. Li, "Rolling circle amplification: applications in nanotechnology and biodetection with functional nucleic acids,” Angew. Chem. Int. Ed. Vol. 47, pp. 63306337, August 2008.

[30] C.M. Fauquet, M. Padidam, R.M. Beachy, "Classification and identification of geminiviruses using sequence comparisons," J. Gen. Virol. vol.76, pp. 249-63, February 1995.

[31] S. D. Wyatt, and J. K. Brown, "Detection of subgroup III geminivirus isolates in leaf extracts by degenerate primers and polymerase chain reaction," Phyto. Vol. 86, pp.1288-1293, August 1996.

[32] P. Pandey, S. Mukhopadhya, A.R. Naqvi, S.K. Mukherjee, G.S. Shekhawat, and N.R. Choudhury, "Molecular characterization of two distinct monopartite begomoviruses infecting tomato in India," Virol. J. vol. 7, pp. 337, November 2010.

[33] D. Deng, P.F. McGrath, D. J. Robinson, and B.D. Harrison, "Detection and differentiation of whitefly-transmitted geminiviruses in plants and vector insects by the polymerase reaction with degenerate primers," Ann. Appl. Biol. vol. 125 pp. 327-336, October 1994.

[34] M.N. Maruthi, S.N. Alam, K.A. Kader, A.R. Rekha, A. Cork, and J. Colvin, "Nucleotide sequencing, whitefly transmission, and screening tomato for resistance against two newly described begomoviruses in Bangladesh," Phyto. vol. 95, pp. 1472-1481, Decmber 2005.

[35] E. P. Rybicki, "A phylogenetic and evolutionary justification for three genera of geminiviridae," Arch. Virol. vol. 139, pp. 49-77, July 1994.

[36] E.P. Rybicki, "A proposal for naming geminiviruses; a reply by the geminiviridae study group chair. Arch Virol," vol. 143, pp. 421- 424, April 1998.

[37] G. Eason, B. Noble, and I. N. Sneddon, "On certain integrals of Lipschitz-Hankel type involving products of Bessel functions," Phil. Trans. Roy. Soc. London, vol. A247, pp. 529-551, April 1955. (references)

[38] J. Clerk Maxwell, A Treatise on Electricity and Magnetism, 3rd ed., vol. 2. Oxford: Clarendon, 1892, pp.68-73.

[39] I. S. Jacobs and C. P. Bean, "Fine particles, thin films and exchange anisotropy," in Magnetism, vol. III, G. T. Rado and H. Suhl, Eds. New York: Academic, 1963, pp. 271-350.

[40] K. Elissa, "Title of paper if known," unpublished.

[41] R. Nicole, "Title of paper with only first word capitalized," J. Name Stand. Abbrev., in press.

[42] Y. Yorozu, M. Hirano, K. Oka, and Y. Tagawa, "Electron spectroscopy studies on magneto-optical media and plastic substrate interface,” IEEE Transl. J. Magn. Japan, vol. 2, pp. 740-741, August 1987 [Digests 9th Annual Conf. Magnetics Japan, p. 301, 1982].

[43] M. Young, The Technical Writer's Handbook. Mill Valley, CA: University Science, 1989.

About Author /(s):

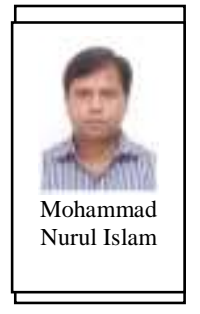

The tool we have developed can be used in detecting ToLCV by Plant pathology clinics 